\title{
Experimental investigation of design parameters for laboratory scale Pelton wheel turbine using RSM
}

\author{
Avita Ayu Permanasari ${ }^{1,}{ }^{1}$, Fajri Faizal Ainul Yaqin ${ }^{1}$, Retno Wulandari ${ }^{1}$, Sukarni ${ }^{1}$ and \\ Poppy Puspitasari ${ }^{1}$ \\ ${ }^{1}$ Mechanical Engineering Department, State University of Malang, 65145 Malang, Indonesia
}

\begin{abstract}
Response Surface Methodology (RSM) is used in this study as an experimental design to obtain optimum conditions for each parameter. This study uses pelton turbines on a laboratory scale. The purpose of this study is to determine the optimum number of buckets and flow rates against turbine performance. The performance measured in this study is turbine efficiency. RSM is used to obtain mathematical equations from the performance of the turbine at optimum conditions. The optimum results obtained from RSM is to improve the performance of Pelton turbines that are 15,7714 (16 pieces) and flow rate of $0.1583 \ell / \mathrm{s}(0.16 \ell / \mathrm{s})$ resulting in turbine efficiency of $29.16 \%$.
\end{abstract}

\section{Introduction}

Indonesia is known as a maritime country that has abundant water resources in which it can be functioned as much as possible as a renewable energy resource. Hence, in fact, the utilization of renewable energy resources to produce electricity is less than $6.8 \%$ of the total available resources [1]. One of the many natural resources available in Indonesia is mineral and energy resources. Some examples have been found of conventional types of energy that can replace oil fuels in the form of gas hydrate and bionic gas off the west coast of Sumatra, southern West Java and the northern part of the Makassar Strait which exceeds all the potential oil and gas that has been managed in the recent time. In addition to conventional energy, there are also non-conventional energies such as solar energy, wind energy and water energy which are generally used as electricity generation.

One tool that can utilize water energy to produce electricity is a water turbine [2]. Water turbines have two types that are impulse turbines and reaction turbines. The impulse turbine works in a non-pressure system, while the reaction turbine works in a pressure system. One example of an impulse turbine is a pelton turbine. The Pelton turbine, patented by Lester Pelton in 1880 that is commonly used in hydroelectric power plants in geographical locations

${ }^{*}$ Corresponding author : avita.ayu.ft@um.ac.id 
where high water heads are available but small flow volumes [3]. However, research on the design structure and efforts to increase the efficiency of low water turbines with a power

of $<1 \mathrm{~kW}$, at very low specific speeds is still inadequate [4]. Therefore, this study was conducted to adjust or determine the performance obtained by pelton turbines on a laboratory scale.

Low-scale pelton turbines are given a limit of $10 \mathrm{~m}$ minimum head, $0.5 \mathrm{\ell} / \mathrm{s}$ water flow, a minimum output power of $0.1 \mathrm{~kW}$ and a minimum jet diameter of $4 \mathrm{~mm}$ [7]. The working principle of pelton turbines is to convert gravitational potential energy into kinetic energy, where the velocity of the water jet increases and hits the bucket turbine then converts it to mechanical energy (shaft rotation), which is quickly converted to electrical energy [5][8]. Turbine buckets used in the effort to generate electricity, are given in the following table [6].

Table.1 Number of Buckets

\begin{tabular}{|c|c|c|c|c|c|c|}
\hline $\mathrm{d}_{0} / \mathrm{D}$ & $1 / 6$ & $1 / 8$ & $1 / 10$ & $1 / 15$ & $1 / 20$ & $1 / 25$ \\
\hline $\mathrm{n}_{\mathrm{b}}$ & 17 to 21 & 18 to 22 & 19 to 24 & 22 to 27 & 24 to 30 & 26 to 33 \\
\hline
\end{tabular}

Available literature usually concentrates on the analysis or optimization of distributor design, injectors, bucket geometry or turbine casings. However, there is not much research published in terms of optimum bucket numbers [7].

This study uses the number of buckets 13 and 15 to prove the effectiveness of the optimization of the Pelton turbine on the number of buckets suggested by the existing literature [6]. The use of 17 bucket quantities is intended to obtain the actual value, on the basis of reference the minimum number of buckets provided. In addition to bucket numbers, this study also uses water flow $(0.11 \ell / \mathrm{s}, 0.13 \ell / \mathrm{s}$, and $0.15 \ell / \mathrm{s})$ to obtain variance values. Flowrate in this study is arranged based on the height or the small head value $(Q=H)$, because the size of the water tank is small and directly connected to the nozzle, the head cannot be adjusted constantly. Changing the head will cause parameters such as velocity coefficients and changing flow rates to affect the flow and characteristics of turbine efficiency [8].

This type of research is correlation research where the aim is to detect the extent to which variations in a factor are related to variations in one or more other factors based on the correlation coefficient. This study uses Response Surface Methodology (RSM) software. RSM is a collection of statistics and mathematical techniques that are useful for developing, improving, and optimizing processes, where the interest response is influenced by several factors (independent variables) [9]. The main idea of this method is to know the effect of the independent variable on the response, get the model between the independent variable and the response and get the process conditions that produce the best response. In addition, the RSM method has the advantages of not requiring large amounts of experimental data and does not require a long time [10].

The purpose of this study is to determine the effect of bucket numbers and optimal flow rate from the performance of small-scale pelton turbines using Response Surface Methodology (RSM). It is expected that the existence of this research can be a source of information as basic data in the process of performance of the Pelton turbine on a laboratory scale.

\section{Material and Methods}

Pelton turbines are turbines that depend on the pressure height or head. This type of turbine works on the flow of direct water and pounds the bucket so that it is pushed backward. The turbine runner gets kinetic energy due to the push of the bucket and causes spinning. This 
shape on the pelton turbine bucket is a double hemispherical cup. The amount of rotation is affected by the weight of the bucket mass and the angle of the distance between the buckets [7].

In this study, the independent variables used are bucket number $(13 ; 15 ; 17$ bucket $)$ and water debit $(0.11 ; 0.13 ; 0.15 \mathrm{l} / \mathrm{s})$. The response variable used to see the performance of the turbine is efficiency. The performance of the water turbine depends on the shaft power produced by the turbine and the efficiency of the turbine mechanics [11]. The laboratory scale pelton turbine specifications used in this study are as follows:

Table 2. Pelton Turbine Specification

\begin{tabular}{|c|c|c|}
\hline Specification & & Value \\
\hline Runner diameter & $:$ & $73 \mathrm{~mm}$ \\
\hline \multicolumn{3}{|l|}{ Bucket } \\
\hline a. Width. & : & $54 \mathrm{~mm}$ \\
\hline b. Height & : & $44 \mathrm{~mm}$ \\
\hline c. Depth & : & $10 \mathrm{~mm}$ \\
\hline Nussle Diameter & : & $8 \mathrm{~mm}$ \\
\hline Pipe Diameter & : & D $1 \frac{1}{2}$ " atau $48 \mathrm{~mm}$ \\
\hline Arm Length & : & $127 \mathrm{~mm}$ \\
\hline Bucket number & : & 13,15 dan 17 \\
\hline Flow & : & $0,11 \ell / \mathrm{s}, 0,13 \ell / \mathrm{s}$ dan $0,15 \ell / \mathrm{s}$ \\
\hline \multicolumn{3}{|l|}{ Main axis } \\
\hline a. $\quad$ Diameter & : & $30 \mathrm{~mm}$ \\
\hline b. Axis Length & : & $370 \mathrm{~mm}$ \\
\hline c. Weight & : & $5 \mathrm{~kg}$ \\
\hline Container body volume & : & $103,488 \mathrm{~cm}^{3}$ \\
\hline \multicolumn{3}{|l|}{ Pump Specification } \\
\hline a. Model & : & Grundfos \\
\hline b. $\quad$ Type & : & NF $13-18$ \\
\hline c. Voltage & : & $220-240 \mathrm{~V}$ \\
\hline d. $\quad$ Hertz & : & $50 \mathrm{~Hz}$ \\
\hline e. Water flow & : & $3.6-17 \mathrm{~m}^{3} / \mathrm{h}$ \\
\hline f. Head & : & $16-6,5 \mathrm{~m}$ \\
\hline g. Output power & : & $1.05 \mathrm{~kW}$ atau $1 \mathrm{HP}$ \\
\hline
\end{tabular}

Figure 1 shows the laboratory scale pelton turbine installation used in this study. 


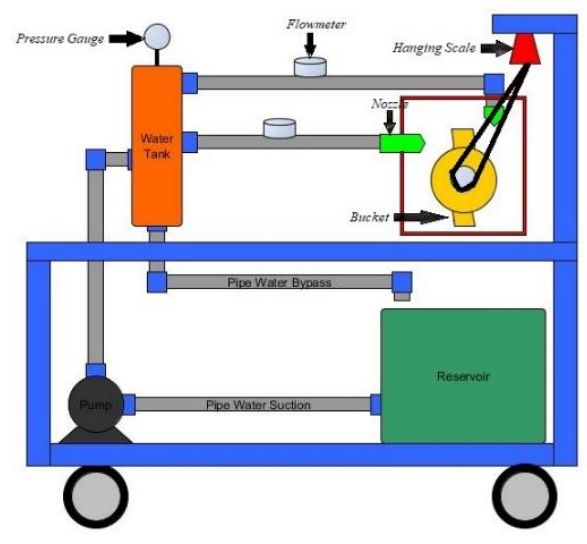

Fig. 1. Pelton turbine installation laboratory scale scheme

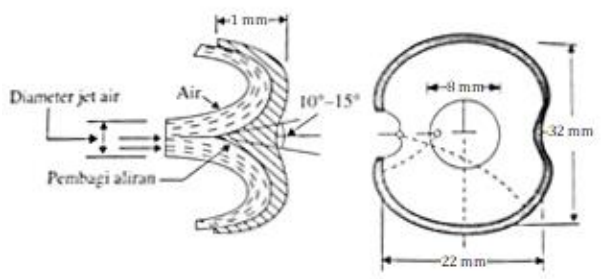

Fig. 2. The dimension of a Pelton Turbine bucket

The performance of the turbine depends on the value of the power produced by the turbine and the total efficiency of the turbine. The turbine power is affected by jet speed and tangential runner speed, while the total efficiency of the turbine is obtained from mechanical efficiency, friction efficiency and hydraulic efficiency [5]. The equation used is shown as follows:

The jet in the nozzle also has a speed shown in the following equation:

$\mathrm{v}_{\mathrm{j}}=\frac{\mathrm{Q}}{\mathrm{A}_{\mathrm{j}}}=\frac{\mathrm{Q} \times 4}{\pi \times \mathrm{D}_{\mathrm{j}}^{2}}\left(\mathrm{~m} \cdot \mathrm{s}^{-1}\right)$

Tangential runner speed can be calculated as follows:

$\frac{\mathrm{v}_{\text {tr }}}{\mathrm{v}_{\mathrm{j}}} \approx 0,5$

The torque on the pelton turbine is determined using the following equation [21]:

$\tau=\mathrm{F} \times \mathrm{r}(\mathrm{Nm})$

The tangential velocity of the turbine runner obtained using this equation:

$\omega=\frac{\mathrm{v}_{t r}}{\mathrm{~L}}(\mathrm{rad} / \mathrm{s})$

The power of the water jet in the Pelton turbine can be calculated as follows:

$\mathrm{P}_{\mathrm{w}}=\rho \times \mathrm{g} \times \mathrm{H} \times \mathrm{Q}$ (watt) 
To power the turbine shaft, the following equation is given:

$P_{S}=\omega \times \tau($ watt $)$

Mechanical efficiency in Pelton turbines is given below:

$\eta_{\mathrm{m}}=\frac{\mathrm{P}_{\mathrm{s}}}{\mathrm{P}_{\mathrm{w}}}(\%)$

The purpose of this study is to obtain a new method in the optimization of parameter design of pelton turbines. From this research, the best parameters of turbines are obtained such as bucket number and water flow to obtain optimum turbine efficiency. Response Surface Methodology (RSM) was used to solve optimization problems in this study.

\section{Experimental Design}

The first step of the surface response method is to find the relationship between the response $\mathrm{y}$ and the independent variable $\mathrm{Xi}$ through the second order polynomial equation. The independent variable is denoted by $\mathrm{X} 1, \mathrm{X} 2, \ldots, \mathrm{Xi}$. These variables are assumed to be controlled by the researcher and influence the response variable $\mathrm{y}$ which is considered a random variable. The second order model is stated with [12]:

$$
\hat{y}=\beta_{0}+\sum_{i=1}^{k} \hat{\beta}_{i} x_{i}+\sum_{i=1}^{k} \hat{\beta}_{i i} x_{i}{ }^{2}+\sum_{i} \sum_{j} \hat{\beta}_{i j} x_{i} x_{j}, i<j
$$

The experimental design method used in this study is the central composite design (CCD). The factor is the observation variable used, while the level is the number of changes in each factor. There are two independent variables that are considered as variables that affect the output power and efficiency of the pelton turbine that is the number of buckets (A) and water flow (B). With two independent variables, the level of each independent variable is encoded with -1 for the low level and 1 for the high level to simplify the calculation. The CCD design in this experiment uses two variables, so that the rotability value is $\left(2^{2}\right)^{1 / 4}=$ 1,412 . Value \pm 1.412 includes the value used for coding. The encoding of the independent variable is calculated using the equation [12]:

$$
\begin{gathered}
x_{1}=\frac{\eta_{1}-15}{2} \\
x_{2}=\frac{\eta_{2}-0,13}{0,2}
\end{gathered}
$$

Minitab program output results and experimental design results can be seen in Table 3. Table 3 shows the experimental design model with 2 factors, 2 levels, and with the addition of 4 axial points. Observation with two factors is observed using two variables, while two levels mean that in each factor is designed in two values of change. 
Table 3. Design and Data of Experimental Results

\begin{tabular}{|c|c|c|c|c|c|}
\hline \multirow{2}{*}{$\begin{array}{c}\text { Std } \\
\text { Order }\end{array}$} & \multicolumn{2}{|c|}{ Variabel Code } & \multicolumn{2}{|c|}{ Factor } & \multirow{2}{*}{$\frac{\text { Respon (y) }}{\text { Efisiensi }}$} \\
\hline & $\mathbf{X}_{1}$ & $\mathbf{X}_{2}$ & $\begin{array}{c}\text { Number of } \\
\text { Bucket }\end{array}$ & $\begin{array}{c}\text { Water } \\
\text { Flow }(\ell / s)\end{array}$ & \\
\hline 1 & -1 & -1 & 13 & 0,11 & 0,1880 \\
\hline 2 & 1 & -1 & 17 & 0,11 & 0,2460 \\
\hline 3 & -1 & 1 & 13 & 0,15 & 0,2809 \\
\hline 4 & 1 & 1 & 17 & 0,15 & 0,2912 \\
\hline 5 & $-1,414$ & 0 & 12,172 & 0,13 & 0,1898 \\
\hline 6 & 1,414 & 0 & 15,771 & 0,13 & 0,2672 \\
\hline 7 & 0 & $-1,414$ & 15 & 0,102 & 0,1954 \\
\hline 8 & 0 & 1,414 & 15 & 0,158 & 0,2978 \\
\hline 9 & 0 & 0 & 15 & 0,13 & 0,2554 \\
\hline 10 & 0 & 0 & 15 & 0,13 & 0,2531 \\
\hline 11 & 0 & 0 & 15 & 0,13 & 0,2543 \\
\hline 12 & 0 & 0 & 15 & 0,13 & 0,2496 \\
\hline 13 & 0 & 0 & 15 & 0,13 & 0,2519 \\
\hline
\end{tabular}

\section{Result and discussion}

In Figure 2, it can be seen that the highest efficiency produced by Pelton turbines is on the order 8 standard of $29.16 \%$, with a total of 15 buckets and a water debit of $0.158 \ell / \mathrm{s}$. The lowest efficiency is shown in standard order 1 at $18.80 \%$, with the number of buckets as many as 13 pieces and water debit of $0.11 \ell / \mathrm{s}$.

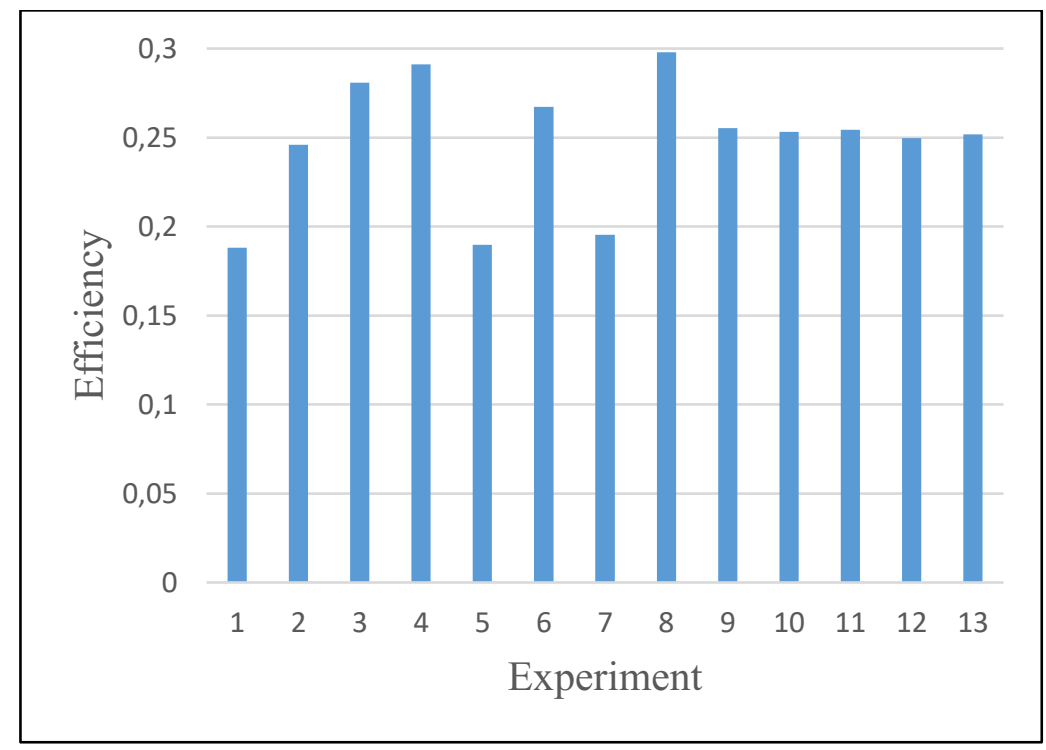

Fig. 3. Efficiency produced by Pelton turbines in experiments

P-Value testing shows a significance level or an opportunity to get a maximum error of $\alpha=5 \%$ (fault tolerance) with a 95\% truth level (confidence interval). Therefore, the smaller the P-Value, the more significant the influence of the independent variable will be. Table 3 shows the output of the second-order response surface method, where the variable number of 
buckets and water flow variable has a P-value of $0.000<0.05$. This shows that the variable number of buckets and water flow has a significant effect on the response. Regression parameters or models simultaneously obtained P-value $0,000<0,05$, so that independent variables have a significant effect on the model formed.

Table 4. Results of Efficiency Anova on the Number of Buckets and Water Flow

\begin{tabular}{|l|c|c|c|c|c|}
\hline Source & DF & Adj SS & Adj MS & F-Value & P-Value \\
\hline Model & 5 & 114,84 & 22,9679 & 96,78 & 0,000 \\
\hline Linear & 2 & 105,931 & 52,9653 & 223,19 & 0,000 \\
\hline Number of Bucket & 1 & 12,565 & 12,5654 & 52,95 & 0,000 \\
\hline Water Flow & 1 & 93,365 & 93,3653 & 393,43 & 0,000 \\
\hline Square & 2 & 3,221 & 1,6103 & 6,79 & 0,023 \\
\hline Number of Bucket*Number of Bucket & 1 & 0,339 & 0,3386 & 1,43 & 0,271 \\
\hline Water Flow*Water Flow & 1 & 2,583 & 2,5832 & 10,89 & 0,013 \\
\hline 2-Way Interaction & 1 & 5,688 & 5,6882 & 23,97 & 0,002 \\
\hline Number of Bucket*Water Flow & 1 & 5,688 & 5,6882 & 23,97 & 0,002 \\
\hline Error & 7 & 1,661 & 0,2373 & & \\
\hline Total & 12 & 116,501 & & & \\
\hline
\end{tabular}

$\mathrm{S}=0,487144$

$\mathrm{R}^{2}=98,57 \% \quad \mathrm{R}^{2}\left(\right.$ adj) $=97,56 \% \quad \mathrm{R}^{2}($ pred $)=89,86 \%$

In table 4 , there is an $\mathrm{R}^{2}$ value that shows a number of 0.98 meaning that the suitability of the model is said to be better if $\mathrm{R}^{2}$ is close to 1 , where there are variations in response due to the influence of high independent variables. It can be explained that the effect of the independent variable on the response variable is $98.57 \%$, while the remaining $1.43 \%$ is influenced by other variables than the independent variable.

Based on the results of the analysis above, the following models are obtained:

Efficiency $=-77.5+2.85$ Number of Buckets +1014 Water Flow +0.0552

Number of Buckets * Number of Buckets - 1523 Water Flow * Water Flow -

29.81 Number of Buckets * Water Flow 


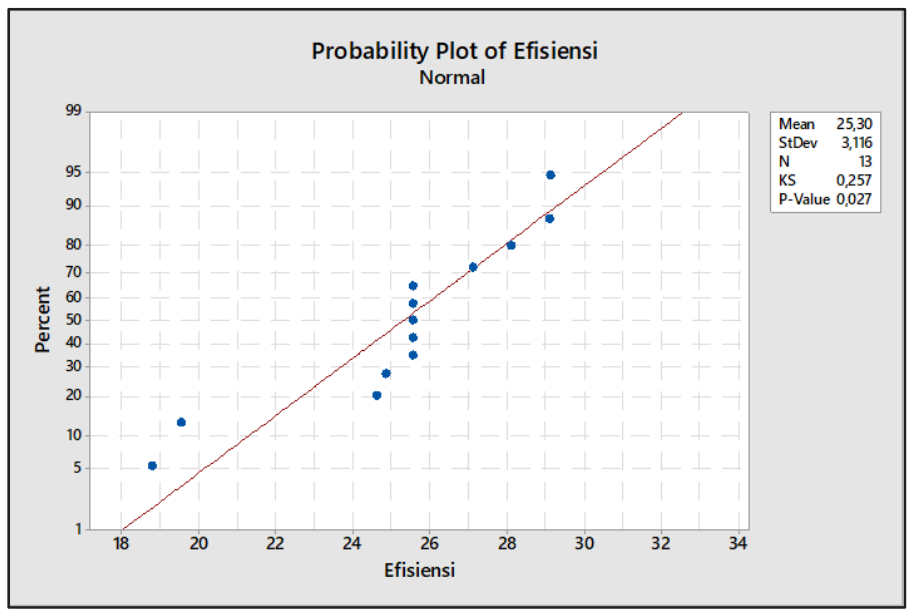

Fig. 4. Test the normal surface model of the Efficiency response

In examining the adequacy of a model, it is not only considered the lack of fit, but also the residual analysis must also be carried out. Figure 3 shows the normal distribution test to observe the model deviation and the residual point must approach the specified straight line. This test is done by comparing the Kolmogorov - Smirnov (KS) statistical test with KS tables at a significant level of 5\%. KS value for efficiency is 0.257 and $\mathrm{KS}$ table is 0.361 . So it can be concluded that the KS count $<$ KS table, which means that the residual normality test has been normally distributed.

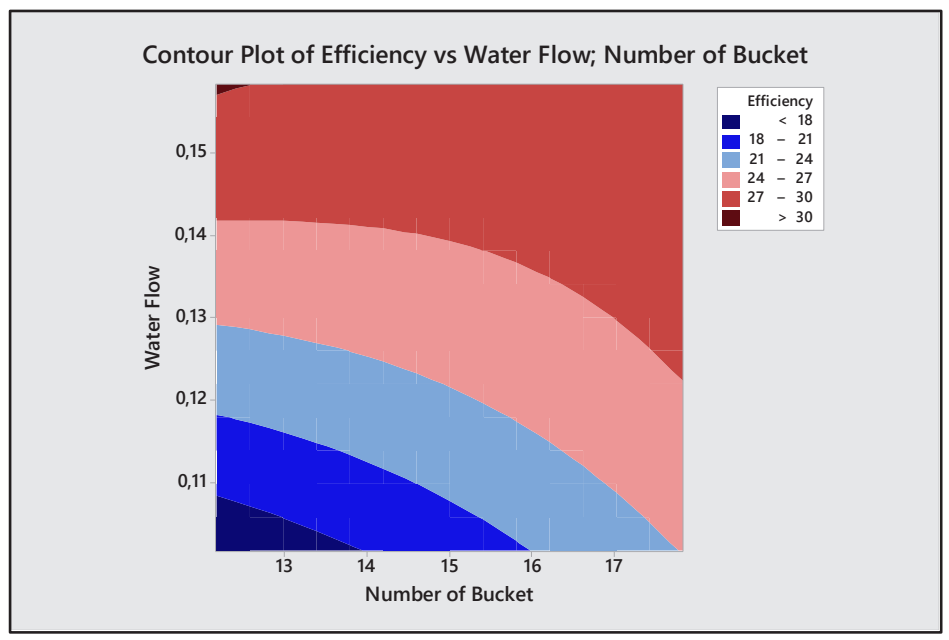

Fig. 5. Efficiency Contour Plot vs Bucket Number, Water Flow 


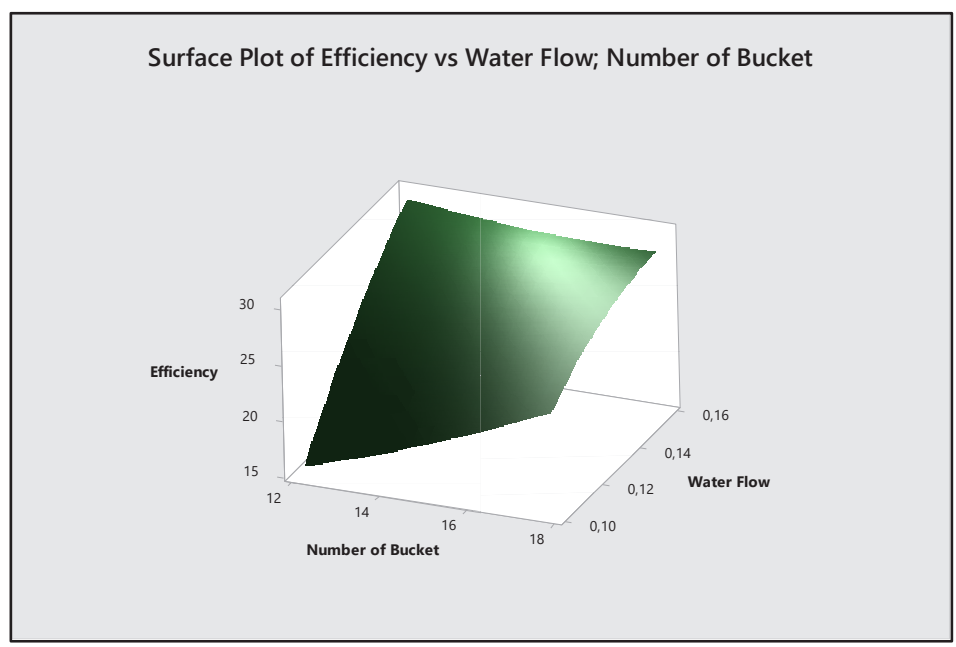

Fig. 6. The normal surface model of the Efficiency response

Figure 4 shows that the contour plot influences the number of buckets and the water flow to efficiency. However, in Figure 5, it shows the response surface contour plots in three dimensions that form the optimum peak. Thus, It can be seen in Figure 5 that the efficiency of pelton turbines is higher when the number of buckets is between levels 16 and 18, while the water flow is at the level of 0.14 and 0.16 .

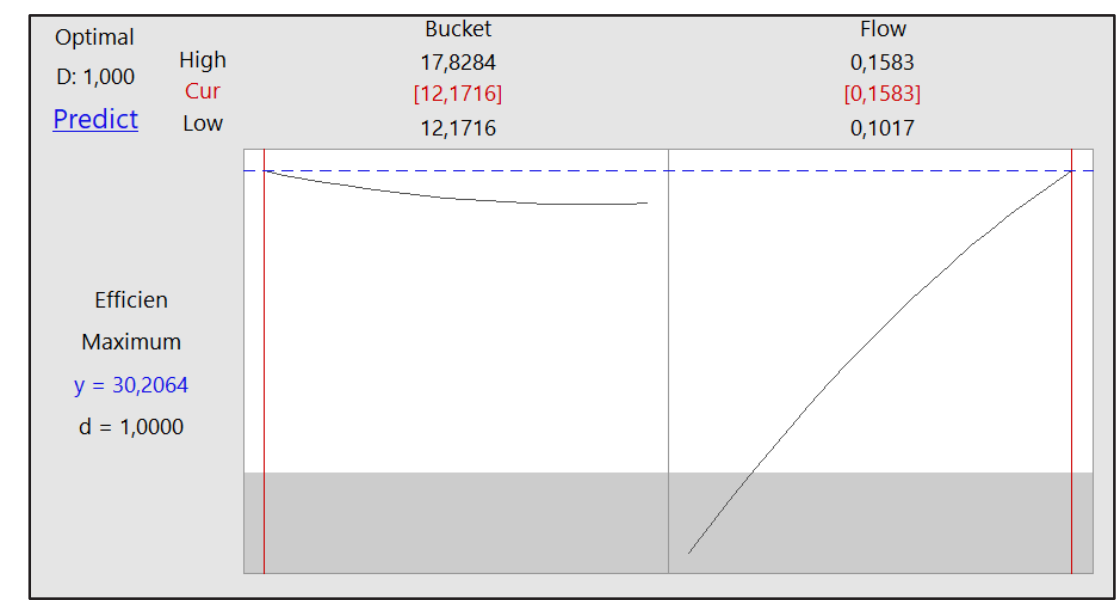

\begin{tabular}{|c|c|c|c|c|}
\hline Solution & Bucket Number & Water Flow & Fit Efficiency & $\begin{array}{c}\text { Composite } \\
\text { Desirability }\end{array}$ \\
\hline 1 & 15,7714 & 0,158284 & 0,291681 & 0,972287 \\
\hline
\end{tabular}

Fig. 7. Optimum response of independent variables

The optimum response from the efficiency of the pelton turbine produced can be seen in Figure 6. Figure 6 shows that the optimum bucket number is 15.77714 (16 pieces) and the optimum water flow is $0.158284(0.16 \ell / \mathrm{s})$. From the results obtained above, it can be 
concluded that the greater the number of buckets and the greater the water flow, the more efficient the pelton turbine will be.

\section{Conclusion}

Based on the data obtained from the results of the study, the number of buckets is as many as 16 pieces and water flow of $0.15 \mathrm{l} / \mathrm{s}$ resulted in the highest turbine pelton efficiency of $29.16 \%$. Based on ANOVA results, the independent variables for bucket number and flow rate have a significant effect on the results of turbine performance. The optimum results obtained from the response surface method to improve the performance of the Pelton turbine are 15,7714 (16 pieces) and a water flow of $0.1583 \ell / \mathrm{s}(0.16 \ell / \mathrm{s})$.

\section{References}

1. N. Kholifah, A. C. Setyawan, D. S. Wijayanto, I. Widiastuti, and H. Saputro, IOP Conf. Ser. Mater. Sci. Eng., 288 (1), 2018

2. R. Wulandari, D. Maharani, and A. A. Permanasari, AIP Conf. Proc., 1887 (2017)

3. D. Agar and M. Rasi, Renew. Energy, 33 (7) pp. 1517-1522 (2008)

4. L. Tang, S. Yuan, and Y. Tang, (2017)

5. S. Aldeen, S. Obayes, M. Abdul, and K. Qasim, 7, 1-7 (2017)

6. S. Data and N. Head, 3.1," pp. 53-109

7. A. Židonis and G. A. Aggidis, J. Hydrodyn., 28 (1), 75-83 (2016)

8. M. Prajapati and N. Saxena, 3026-3027 (2018)

9. S. V. Marija Radojkovića, Zoran Zekovića, Stela Jokićb, Rom. Biotechnol. Lett., 17 (3) 7295-7308 (2012)

10. T. K. Trinh and L.-S. Kang, Environ. Eng. Res., vol. 15, no. 2, pp. 63-70, 2010

11. K. A. Lempoy, R. Soenoko, S. Wahyudi, and M. A. Choiron, J. Eng. Sci. Technol., vol. 12 , no. 8, pp. 2175-2186, 2017

12. A. I. Khuri, Biometrics Biostat. Int. J., vol. 5, no. 5, 2017 